\title{
DESAFIOS DO COORDENADOR NA GESTÃO DE CURSOS DE GRADUAÇÃO: UM ESTUDO COMPARATIVO EM UNIVERSIDADE PÚBLICA E PRIVADA
}

http://dx.doi.org/10.5902/2318133834412

\author{
José Euzébio de Oliveira Souza Aragão ${ }^{1}$ \\ Paulo Antonio Da Graça Lima Zuccolotto² \\ Maria Aparecida Bovério 3 \\ Vanessa Terra Pereira ${ }^{4}$
}

\section{Resumo}

A figura do coordenador de curso existe desde a década de 1960 no ensino superior brasileiro, mas foi somente a partir da lei n. 9.394/96 que o coordenador de curso assumiu um papel fundamental na gestão dos cursos de graduação. Outro fator que ressignificou o papel do coordenador foi a implantação das políticas públicas de avaliação do ensino superior, em meados da década de 1990, e as transformações que levaram a uma diversificação e diferenciação da educação superior no Brasil, configurando a reestruturação com viés neoliberal. A partir de pesquisa bibliográfica, análise documental e observação participante, discute-se o papel, o perfil e os desafios do coordenador de curso como gestor acadêmico, identificando modelos de gestão em uma universidade pública e em uma universidade privada.

Palavras-chave: coordenador de curso; gestão de curso de graduação; modelos de gestão.

\section{COORDINATOR'S CHALLENGES IN THE MANAGEMENT OF UNDERGRADUATE COURSES: A STUDY IN PUBLIC AND PRIVATE UNIVERSITY}

\begin{abstract}
The coordinator's figure has existed since the 1960 in Brazilian higher education, but only from the 9.394/96 law, that the course coordinator took a key role in the management of undergraduate courses. Another factor that relates the role of the coordinator was the implementation of public policies for higher education evaluation in the mid-1990 and the transformations that led to diversification and differentiation of higher education in Brazil, Setting up restructuring with neoliberal bias. From bibliographic research, documentary analysis and participant observation, our work discusses the role, profile and challenges of the course coordinator as an academic manager, identifying management models at a public university and in a private university. Key-words: course coordinator; graduation course management; management models.
\end{abstract}

Universidade Estadual Paulista Júlio de Mesquita Filho, campus de Rio Claro, Brasil. E-mail: aragao@rc.unesp.br.

2 Pontifícia Universidade Católica de Campinas, Brasil. E-mail: pzuccolotto@terra.com.br.

${ }^{3}$ Faculdade de Tecnologia de Sertãozinho/SP, Brasil. E-mail: mariaboverio@hotmail.com.

${ }^{4}$ Universidade Estadual Paulista Júlio de Mesquita Filho, campus de Marília, Brasil. vantpereira@gmail.com.

n. 17

Pub. contínua 2019

p. $1-16$ 


\section{Introdução}

Aigura do coordenador de cursos de graduação já existe desde a década de 1960 no ensino superior brasileiro, mas foi somente a partir da lei n. 9.394/96 que o coordenador de curso assumiu um papel fundamental na gestão dos cursos de graduação das instituições de ensino superior brasileiras. Além da referida lei, outro fator que ressignificou o papel do coordenador de cursos foi a implantação das políticas públicas de avaliação do ensino superior, a partir de meados da década de 1990.

Mais do que implantação de políticas públicas de avaliação do ensino superior, desde a década de 1990, esse nível de ensino passou por transformações que incluem o Programa Universidade para Todos, o Programa de Apoio a Planos de Reestruturação e Expansão das Universidades Federais, a oferta de cursos superiores a distância, as políticas de ações afirmativas e, em geral, uma diversificação e diferenciação da educação superior no Brasil: uma reestruturação da educação superior no Brasil que inclui, especialmente, um novo padrão de modernização e gerenciamento para o campo universitário.

Esse modelo de gestor e de gestão vai buscar na Teoria Geral de Administração os seus fundamentos. O pressuposto dessa concepção de administração educacional é o de que administrar uma escola é equivalente à administração de uma empresa. De fato, quando nos referimos a gestão, estamos falando de uma atividade, ou de uma série de atividades integradas, destinadas a permitir que certa combinação de meios possa gerar uma produção de bens ou serviços, mas cabe à administração escolar criar condições que favoreçam o processo educativo escolar e os resultados são consequências da conjugação de inúmeros fatores. A eficácia e eficiência do processo escolar acontece a partir da mediação entre os recursos e os resultados alcançados, mas no caso da escola, a administração é orientada pelo projeto político-pedagógico.

Neste texto discute-se o papel, o perfil e os desafios do coordenador de curso como gestor acadêmico, identificando modelos de gestão em uma universidade pública e em uma universidade privada. Utilizamos pesquisa bibliográfica, análise documental e observação participante para atingir nossos objetivos. Dentre os documentos analisamos estatutos, regimentos, portarias, resoluções normativas e normas das instituições pesquisadas. Três dos quatros autores deste trabalho têm experiência de mais de uma década em gestão de cursos e instituições, sendo que dois deles atuam, atualmente, nas instituições pesquisadas.

Os modelos de gestão: revisitando as teorias de administração em busca de uma teoria da administração escolar

Tanto a palavra administração, quanto gestão são de origem latina, gerere e administrare. Gerere significa conduzir, dirigir, governar. Administrare tem aplicação específica no sentido de gerir um bem, defendendo os interesses dos que o possuem (Ferreira; Reis; Pereira, 1997).

Para Aktouf (1996), termos como gestão, administração, ou gerir, administrar, ou ainda gestor, administrador, gerente, dirigente criam mais confusões do que ajudam. 0 autor prefere considerar esses termos como sinônimos. Motta (1999) concorda com 
Aktouf (1996) quando afirma não ver grandes dissociações entre os termos executivo, gerente ou administrador. Todos trabalham essencialmente nas decisões e, mais que seus superiores, estabelecem sentidos de direção para suas empresas e instituições.

No Brasil as palavras administrador e gerente designam qualquer posição de direção e chefia. O termo administração, desgastado por sua prática equivocada, perdeu sua imponência pela palavra gerência. Até a década de 1970, no Brasil, a palavra administrador, apesar de pouco usada, tinha a sua importância mais acentuada do que a de gerente. Dirigentes de alto nível eram preferencialmente administradores. Gerentes eram considerados os de hierarquia mais baixa ou os que exerciam funções em pequenos comércios. O desgaste da palavra administração revigorou a expressão gerência, que passou a designar funções executivas de grandes empresas (Motta, 1999).

$\mathrm{Na}$ década de 1990 o termo gestão ganhou espaço, acrescentando algumas novidades, sem, entretanto, significar uma mudança conceitual. Para Motta (1999), o termo gestão ganhou espaço por sua generalidade e pureza modernas, ainda não desgastado por uso e desusos e exemplo dos termos administração e gerência.

Na verdade, quando estamos falando de gestão, ou administração,ou gerência,

estamos falando de uma atividade, ou mais precisamente, de uma série de atividades integradas e interdependentes, destinadas a permitir que certa combinação de meios (financeiros, humanos, materiais etc.) possam gerar uma produção de bens ou serviços economicamente e socialmente úteis e, se possível para a empresa, com a finalidade lucrativa, rentáveis. (Aktouf, 1996, p. 25)

Essa atividade, ou série de atividades integradas e interdependentes, foi sistematizada e definida a partir de princípios e funções por Taylor e Fayol desde o início do século 20 e daí até os dias atuais surgiram contribuições das mais variadas tentando transformar a administração em uma ciência, ou seja, embasada em princípios científicos, muito distantes do senso comum na condução das organizações, configurando modelos de gestão.

Quando se fala em gestão é imperativo entender que os ambientes organizacionais tanto internos - recursos, estrutura, etc. -, quanto externos - grau de competitividade ou público a ser atendido - são únicos. Portanto desta compreensão nasce a estratégia gerencial para se atingir os objetivos. Conhecer, portanto, os ambientes organizacionais é condição fundamental para indicar a receita adequada para a organização administrada.

Em gestão, quando se refere a modelo segundo Robbins (1978) citado por Pereira e Santos (2001) se induz a uma representação simplificada do ambiente que ajuda na compreensão das relações complexas do mundo organizacional. Objetivamente os modelos podem substituir complexidade por simplicidade: "Assim, tratando-se de uma descrição abrangente, que procure refletir toda a realidade organizacional, espera-se que todos os elementos básicos constituintes de uma organização qualquer - tarefas, estruturas, pessoas e tecnologias sejam contemplados" (Pereira; Santos, 2001, p. 39).

Para Maximiano (2012) os modelos de gestão, normalmente, estão associados ao ambiente de competitividade a que a organização está exposta. Segundo o autor ambientes competitivos mais intensos requerem modelos orgânicos de gestão cujas características estão em estruturas mais flexíveis, menos burocratizadas, participativas, 
entretanto menos especializadas. Organizações mecanísticas ou mecanicistas estão associadas a ambientes mais estáveis cuja necessidade de especialização é maior, uma vez que o grau de competitividade é determinado por estabilidade e profundidade na relação com o mercado.

Antes de definirmos os tipos de gestão na concepção de Aktouf (1996), citamos as reflexões de Abreu (1982) sobre a evolução da teoria administrativa. Abreu (1982) distingue quatro momentos cruciais no desenvolvimento da teoria organizacional. 0 primeiro momento corresponde ao grupo de engenheiros americanos Taylor, Gilbreth e Gilbreth, denominado de grupo mecanicista, "cuja concepção se resumia, basicamente, no estudo da organização vista de baixo para cima ou, melhor dizendo, ao nível operacional dos trabalhadores manuais" (Abreu, 1982, p. 41). Ainda a esse primeiro momento soma-se as ideias de Fayol - e Urwick, Gulick, etc. -, também engenheiro, mas francês, "que toma como referência um patamar mais alto da organização, ou seja, a análise do papel do dirigente e, também da própria estrutura organizacional da empresa" (Abreu, 1982, p. 41), sendo por isso chamado de grupo anatômico.

À fusão das ideias desses dois grupos atribui-se o nome de Escola Clássica, que tem como preocupações fundamentais a definição de um modelo de organização do trabalho - no chão de fábrica e na cúpula- que busca a eficiência e produtividade por meio de princípios que visam substituir o empirismo.

O segundo momento origina-se nas experiências de Elton Mayo e Fritz Roethlisberger, realizadas entre 1927 e 1932 na Western Eletric Company, em Hawthorne, Chicago. Partindo de premissas da Escola Clássica, Mayo e Roethlisberger descobriram a importância do elemento humano e sua complexidade para o desempenho organizacional. Um desdobramento da chamada Escola das Relações Humanas, os comportamentalistas ampliaram os estudos do primeiro, chamando a atenção às questões de motivação, participação, democratização do ambiente de trabalho, trabalho em grupo e outros aspectos correlatos.

O terceiro momento da evolução da teoria organizacional lança mão do conceito advindo da biologia - o de sistemas - para analisar as organizações. Essa vertente vê as organizações como sistemas abertos, que interagem com o ambiente em que atuam, recebendo insumos e exportando produtos ou serviços. Por outro lado, as organizações são compostas por subsistemas internos, com interação dinâmica uns com os outros e, portanto, mutuamente dependentes. Essa compreensão da organização traz à tona o fato de que as organizações só poderão sobreviver em um ambiente de alta mutabilidade na medida em que desenvolvam mecanismos de adaptação contínua ao meio ambiente.

O último momento segundo Abreu (1982), é chamado de enfoque contingencial e dá sequência às ideias do enfoque sistêmico explicitado anteriormente. O enfoque contingencial preconiza que não há princípios ou critérios universais para se administrar as organizações. O desenho organizacional deve corresponder ao ajustamento entre a empresa e o seu ambiente.

Essa perspectiva, Teoria das Contingências, entende que situações diferentes exigem práticas diferentes podendo utilizar as teorias tradicionais clássicas, comportamentais e de sistemas separadamente ou de maneira combinada na busca de soluções para as organizações (Silva, 2001). 
Do modelo mecanicista/anatômico ao modelo contingencial, passando pelos modelos das relações humanas/comportamental e sistêmico vemos o incremento de novas perspectivas acerca das organizações. Contudo, parece prevalecer uma ideia de ecletismo entre os diversos enfoques, na medida em que uma concepção não inviabiliza as outras, permitindo-se e admitindo-se a aplicação de vários enfoques em uma mesma organização, salvo alguns aspectos conflitantes. O que queremos enfatizar é que as ideias de Taylor e Fayol, ao ressaltarem os aspectos da organização do trabalho e da eficiência em primeiro plano, não menosprezam o papel do elemento humano, apenas o considera secundário diante de condições objetivas: sociais, econômicas, políticas etc. Ao mesmo tempo, os pressupostos da Escola das Relações Humanas e dos Comportamentalistas não se afiguram como opositores aos anseios de produtividade da Escola Clássica. E nem mesmo o fazem os sistêmicos, de maneira que podemos inferir que não há embates ideológicos no campo da administração. De certa forma, as teorias se complementam e o conhecimento a respeito das organizações se acumula, elaborando o ecletismo citado anteriormente.

De maneira geral diríamos que a Escola Clássica, acrescida do modelo burocrático não tratado nos quatro momentos do desenvolvimento da teoria organizacional delineiam um modelo de gestão chamado de tradicional, resultado de aspirações e experiências que foram se consolidando e atingiram seu apogeu nas ideias de Taylor Fayol. O modelo burocrático remete a algumas características, a partir dos tipos ideais de organizações, de Max Weber. Podemos destacar algumas dessas características como centralização das decisões, regulamentação pormenorizada, previsibilidade, formalismo, impessoalidade e obsessão por documentos escritos. Essas características apresentam a organização burocrática como um modelo organizacional assentada no princípio da racionalidade, que se traduz na previsibilidade, na consensualidade sobre os objetivos, na adequação dos meios aos fins, nos processos de decisão e planejamento estáveis.

A gestão tradicional pode ser comparada ao exército e a máquina, e a colmeia e o formigueiro. Simboliza a previsibilidade, a disciplina, a ordem, a lógica mecânica, a especialização de funções, a conduta racional, mas também uma concepção do ser humano e de relações de trabalho carregadas de aspectos negativos para o desempenho e produtividade (Aktouf, 1996). Embora fortemente alicerçada nas ideias da escola Clássica, a gestão tradicional inclui também as correntes da Psicologia e da Sociologia Industrial que "acrescenta a crença na possibilidade de manipular e de modificar as percepções, as convicções e as atitudes dos indivíduos para canalizá-las no sentido desejado pelos dirigentes" (Aktouf, 1996, p. 32). Para esse autor, a gestão tradicional engloba o conjunto de teorias administrativas anteriores às correntes da cultura organizacional e da qualidade total.

A gestão renovada ou inovadora, por outro lado, típica de organizações modernas, resolve os problemas organizacionais utilizando criatividade e inovação. Aktouf (1996) enfatiza que o estilo de gestão inovador/renovado tem como fundamento um novo modo de relação entre dirigentes e dirigidos, empregadores e empregados e, sobretudo, entre empregados e empresas. Para o autor apenas poucas organizações no mundo têm efetivamente caminhado para uma real renovação de sua gestão. Na verdade, o que impera, é o modelo tradicional, taylorista, burocrático e conservador, acrescido de alguns aspectos modernizantes. 
A gestão inovadora mexe com a questão do poder nas organizações, com as relações de trabalho e com o processo milenar de conceber e executar, mas de forma coletiva e democrática. Essa gestão inovadora requer mudança da cultura organizacional, trabalho em equipe, autonomia das equipes quanto a objetivos e desempenhos, diminuição dos níveos hierárquicos e pela reaproximação das relações entre as funções da empresa, de forma integrada.

Segundo Russo (2004), "no Brasil, a administração educacional tem se pautado, teórica e praticamente, no paradigma da administração empresarial que encontra na Teoria Geral da Administração a expressão do seu pensamento e a formulação de suas práticas" (p. 27). O pressuposto dessa concepção de administração educacional é o de que administrar uma escola é equivalente à administração de uma empresa. Outros argumentos são: a administração é uma técnica, ou seja, conjunto de princípios e métodos que asseguram melhores resultados; é universal, já que se aplica a qualquer tipo de organização, a qualquer situação e contexto e, por último, é neutra, pois foi construída de modo desinteressado e à parte dos conflitos que se manifestam nas organizações (Russo, 2004).

O autor contesta tais argumentos, considerando a Teoria Geral da Administração um instrumento de dominação do capital sobre o trabalho para conseguir um crescente aumento da eficácia e eficiência do trabalho, ou de sua produtividade. Não se registram, portanto, nas teorias da Administração, estudos que reflitam os interesses dos trabalhadores e adotem uma perspectiva da democratização do poder nas organizações como apregoa a gestão inovadora/renovada.

As propostas de superação do paradigma da administração empresarial como fundamento da administração escolar, segundo Russo (2004), têm por hipótese a natureza específica do processo pedagógico de produção escolar, que

significa produzir um conhecimento sobre o trabalho pedagógico escolar e sua organização, voltado a melhorar qualitativa e quantitativamente a formação de sujeitos da educação, isto é, que seja um conhecimento iluminador da prática e indicador dos caminhos que a transformam em verdadeira práxis criadora e reflexiva; que venha oferecer contribuições para o aumento da produtividade da aprendizagem dos alunos e produza efeitos contrários aos da burocracia que, enquanto forma de estruturação das organizações, é uma maneira específica de exercício do poder que favorece o autoritarismo e dificulta a participação e a democratização das organizações. (Russo, 2004, p. 30)

À administração escolar cabe criar condições que favoreçam o processo educativo escolar e os resultados são consequências da conjugação de inúmeros fatores (Russo, 2004). O foco são os resultados tendo por base o projeto político-pedagógico e não a ideia de lucro.

Goldbarg (1998), apontando dificuldades de aplicação dos sistemas de qualidade total na área de educação, contribui para a necessidade de construção de uma teoria da administração escolar desvinculada da Teoria Geral da Administração. Para esse autor, o sistema escolar possui uma estrutura e um relacionamento entre os subsistemas significativamente diferentes do sistema industrial: 
Em nenhuma atividade produtiva, o aspecto afetivo é tão significativo quanto o é na educação. A dimensão afetiva tem um papel enorme no despertar do potencial dos alunos e professores e, em consequência, na qualidade do ensino. Os laços que podem unir mestres e alunos vão além daqueles que ligam um produtor ao seu cliente mais simpático. Um mestre não dá aula, mas influencia na formação de uma pessoa. A peculiaridade das relações professor $x$ aluno exigirá, sem qualquer sombra de dúvida, uma adaptação no conceito de cliente. (Goldbarg, 1998, p. 57)

Um segundo aspecto é a interdisciplinaridade: "Uma escola é uma organização que possui processos extraordinariamente interdependentes, mas, mesmo assim, deve preservar a iniciativa, a criatividade e a independência intelectual de todos os seus componentes. A interdisciplinaridade é um desafio para a padronização" (Goldbarg, 1998, p. 57).

Por último, o aspecto da importância do compromisso social. Toda empresa tem um compromisso com a sociedade, variando o grau de acordo com a atividade praticada, mas, segundo o autor:

O caso da educação é diametralmente oposto. É ela exatamente a parte do tecido social que recebe uma das amplas e contínuas delegações de influenciar o futuro da própria sociedade. Não importando se pública ou particular, em virtude de seu papel delegado, toda escola tem um forte dever com o social, compromisso esse que engloba a obrigação com um serviço de excelência e extensivo ao maior número de pessoas. Absolutamente nenhuma escola, em nenhum nível, em nenhum lugar da Terra pode ser encarada com um simples negócio. Essa mentalidade simplesmente desqualifica a organização para exercer a delegação de educar. Moldar o cidadão não pode ser encarado apenas como um negócio como outro qualquer. Pensando assim, estaríamos reduzindo os seres humanos no nível das coisas barganháveis e quantificáveis fiduciariamente. [...] Negociar a educação é um dos mais lamentáveis e grosseiros erros que um administrador pode cometer. A escola só poderá alcançar a qualidade com uma dose de dedicação e compromisso que transcende o foco no resultado financeiro. (Goldbarg, 1998, p. 58)

Além desses aspectos, frisa Goldbarg (1998, p. 54):

a) o contexto educacional é mais sofisticado e complexo;

b) os impactos sociais da atividade produtiva educacional são um dos mais importantes aspectos do fenômeno;

c) os clientes possuem necessidades e expectativas extremamente sofisticadas e conflitantes;

d) os ciclos de vida são contados dentro de outras escalas;

e) existe outro nível de envolvimento emocional em jogo: o do crescimento da alma humana e não somente de sua satisfação dimensional. (Goldbarg, 1998, p. 54)

Portanto, se gerir recursos nas organizações é uma tarefa complexa em função das características e das finalidades da administrada, a gestão da instituição escolar adota dimensões de maior complexidade uma vez que a tangibilidade dos resultados não deve ou não pode medidas no curto prazo como um fato meramente econômico ou a eficiência na utilização dos recursos. Os resultados de uma instituição escolar serão medidos ao longo de um percurso que tangibilizará o nível de eficácia alcançada tendo como referência seu objetivo e posicionamento.

Regae: Rev. Gest. Aval. Educ.

Santa Maria

v. 8

n. 17

Pub. contínua 2019

p. $1-16$ 


\section{Coordenação de cursos de graduação: exigência legal ou necessidade de gestão?}

A figura do coordenador de cursos de graduação já exista desde a década de 1960 no ensino superior brasileiro, mas foi somente a partir da lei n. 9.394/96 que o coordenador de curso assumiu um papel fundamental na gestão dos cursos de graduação das instituições de ensino superior brasileiras. O curso tomou a forma de uma unidade acadêmico-administrativa dentro das instituições e seu coordenador passa a ser visto como gestor dessa unidade.

A importância do coordenador de curso no cenário da educação superior no Brasil se deve, em grande parte, a não exigência de departamentos no âmbito das instituições de ensino superior. A maioria das instituições extinguiu-os de suas estruturas organizacionais, preferindo acolher a ideia de coordenação de curso e atribuindo ao novo setor a responsabilidade pela direção e pelo sucesso dos cursos superiores (Franco, 2002).

Além da referida lei, outro fator que ressignificou o papel do coordenador de cursos foi a implantação das políticas públicas de avaliação do ensino superior a partir de meados da década de 1990. A experiência brasileira de avaliação educacional não é recente, já havia experiências na pós-graduação desde a década de 1970 e outras iniciativas durante a década de 1980, mas foi somente a partir de 1995, com a lei n. 9.131, que o governo federal definiu uma sistemática de avaliação coordenada pelo MEC. A partir de então implantou-se avaliações periódicas das instituições e cursos de graduação, utilizando-se procedimentos e critérios abrangentes e complexos:

Essa política de avaliação do ensino superior, desenvolvida ao longo dos dois mandatos do Presidente Fernando Henrique Cardoso (de 1995 a 1998 e de 1999 a 2002) causou polêmica em toda a comunidade acadêmica e teve os holofotes voltados, principalmente, para o ENC, que possibilitava a divulgação, pela primeira vez, de um ranking dos cursos de graduação no Brasil. (Aragão; França; Zuccolotto, 2016, p.148)

Mais do que implantação de políticas públicas de avaliação do ensino superior, desde a década de 1990 esse nível de ensino passou por transformações que incluem o Programa Universidade para Todos, o Programa de Apoio a Planos de Reestruturação e Expansão das Universidades Federais, a oferta de cursos superiores a distância, as políticas de ações afirmativas e, em geral, uma diversificação e diferenciação da educação superior no Brasil. De fato, essas políticas "configuram a existência de uma reestruturação da educação superior no Brasil, que inclui, especialmente, um „novo "padrão de modernização e gerenciamento para o campo universitário, inclusos no novo paradigma de produção capitalista e na reforma da administração pública do Estado" (Catani; Oliveira, 2000, p. 63).

Nesse cenário de reestruturação produtiva e de reforma da administração pública do Estado, ganharam força as teses neoliberais ou neoconservadoras que identificam a crise como sendo de responsabilidade do Estado, particularmente do Estado de bem-estar social, que as políticas de cunho social o levaram a uma crise fiscal. 
Essa reestruturação afetou a educação: em dez anos as matrículas em cursos superiores, presenciais e a distância, mais que dobraram: de 3.036.113, em 2001, passaram para 6.379.299 em 2010. Apesar do total de matrículas - federais, estaduais, municipais e privadas - ter alcançado um crescimento de $110 \%$ nesse período, o fato é que a rede privada continua sendo a grande responsável pela ensino superior no país.

É nesse contexto que se insere uma discussão sobre a gestão de cursos de graduação. A figura do coordenador de curso deixou de ser simbólica e se tornou um imperativo para o sucesso dos cursos de graduação. A denominação de gestor é atualmente a mais adequada por abranger as diversas nomenclaturas encontradas para os dirigentes de cursos. O gestor do curso, principalmente os de IES privadas, envolve-se nas questões pedagógicas, nas questões administrativas, de infraestrutura, tendo como eixo o projeto pedagógico do curso:

Tanto no passado como no presente, ainda não se chegou a um denominador comum quanto às funções, às responsabilidades, às atribuições e aos encargos do Coordenador de Curso. Diz-se ser ele o gerente do Curso. Chega-se mesmo a afirmar que é o dono do Curso. $\mathrm{Na}$ realidade, predominam na figura do Coordenador de Curso e, de certa forma na concepção geral, apenas os encargos acadêmicos. São relegadas por ele as responsabilidades não acadêmicas, ou seja, as responsabilidades e funções gerenciais, políticas e institucionais, no estrito sentido dessas expressões. (Franco, 2002, p. 3)

De fato, qualquer pesquisa bibliográfica sobre gestão de cursos de graduação vai resultar em poucas referências e, em geral, a artigos científicos empíricos que visam ou definir as atribuições e responsabilidades do gestor de cursos, ou descrever as atribuições em instituições de ensino superior, na maioria das vezes revelando suas próprias experiências e em busca de um gestor ideal.

Nesse sentido, Franco (2002) descreve as funções necessárias para atuação de um coordenador de curso ideal. São elas: funções políticas, gerenciais, acadêmicas e institucionais. envolvem liderança; ser um animador proativo; ser o representante de seu curso; ser o fazedor do marketing do curso; ser responsável pela vinculação do curso com os anseios e desejos do mercado; ser o responsável pela supervisão das instalações físicas; laboratórios e equipamentos do curso; ser o responsável pela indicação da aquisição de livros; materiais especiais e assinatura de periódicos necessários ao desenvolvimento do curso; ser responsável pelo estímulo e controle da frequência docente; pela indicação da contratação de docentes e, logicamente, pela indicação da demissão deles; ser o responsável pela elaboração e execução do projeto pedagógico do curso; ser responsável pela qualidade e pela regularidade das avaliações desenvolvidas em seu curso; estimular a iniciação científica e de pesquisa entre professores e alunos; ser responsável pelo sucesso dos alunos de seu curso nas avaliações em larga escala do MEC; ser responsável pelo acompanhamento dos antigos alunos do curso, dentre outras atribuições.

Essas quatro funções, segundo Jacobucci e Jacobucci (2008), mitificam o profissional que assume o cargo de coordenador e influenciam os administradores universitários a exigir uma sobre carga de trabalho dos coordenadores pela jornada de 40 
horas semanais. Embora pareça uma missão impossível, essas funções são exigidas por muitas instituições particulares de ensino superior, sem que a contrapartida, a remuneração chegue próxima aos valores pagos aos executivos de grandes empresas.

Percebe-se, então, a necessidade de envolvimento em variadas funções que vão além dos saberes construídos em sua formação e exercício da docência, respondendo tanto pedagógica, política, quanto administrativamente pelo curso que coordena. Dessa forma, coordenar um curso exige um envolvimento em questões políticas, gerenciais, acadêmicas e institucionais que remetem a uma contrapartida para com a sociedade, docentes, salas de aula, instituição e atores, apontando para uma amplitude de saberes necessários para o exercício da função (Noguez; Tillmann; Duarte, 2016).

Outro aspecto importante de ressaltar é que na maioria das vezes o gestor do curso tem como parâmetros de gestão o que se preconiza nas avaliações institucionais. Normalmente esses parâmetros são lidos como um caderno de normas o que invariavelmente tem como objetivo do cumprimento de dispositivos legais sem que, no entanto, estejam orientados por um modelo de gestão concebido pela instituição. $O$ modelo de gestão deverá ter como consequência o entendimento sobre a perpetuação da instituição de ensino além, é claro, o de atender os dispositivos legais e seus critérios de avaliação.

Os atuais mecanismos e instrumentos de avaliação externa a que os cursos de graduação estão expostos não se resumem ao ENADE. Além do governo que exerce uma função reguladora oficial da Educação Superior, o mercado produziu ao longo dos últimos anos ferramentas destinadas a aferir a qualidade de cursos em Instituições de Ensino Superior, traduzidos em rankings. O que importa é que o coordenador de curso deve se apropriar das políticas de avaliação e que dentre suas tantas atribuições, desenvolva ações que impactem nos resultados das avaliações (Aragão; França; Zuccolotto, 2016, p. 158)

\section{As instituições pesquisadas: caracterização, estrutura e gestão de curso}

As duas universidades, objeto deste artigo, estão localizadas no interior do Estado de São Paulo. A primeira IES pesquisada é uma instituição privada, comunitária, confessional e filantrópica, criada em 1941. Iniciou com a Faculdade de Filosofia, Ciências e Letras e a Faculdade de Ciências Econômicas oferecendo, à época, oito cursos. Em 1955 tornou-se universidade, com aprovação do então Conselho Federal de Educação. Possui cerca de 16.000 alunos na graduação, alocados em dois campi na mesma cidade, com cursos nas diversas áreas, além dos alunos em pós-graduação - lato e stricto sensu e de extensão. Atualmente oferece 61 cursos de graduação, nove cursos de mestrado e três de doutorado, além de 21 opções de pós-graduação lato sensu.

O coordenador de curso, que nesta IES recebe a denominação de diretor de Faculdade. Cada Faculdade pode oferecer mais de um curso e, portanto, neste caso, diretores adjuntos são nomeados para a coordenação de curso. A direção de Faculdade se situa no quarto nível hierárquico da instituição, subordinado a uma direção de centro. Os centros são unidades organizacionais básicas que se constituem por faculdade e estas por cursos. Além das faculdades, cada centro possui um Núcleo de Pesquisa e 
Extensão, que coordena essas atividades no nível do Centro. Atualmente a IES possui cinco centros: Centro de Ciências Exatas, Centro de Ciências da Saúde, Centro de Ciências Humanas e Sociais, Centro de Ciências Econômicas e Administrativas e Centro de Comunicação e Linguagem.

O ensino da graduação é feito por cursos com supervisão próxima de Conselho de Faculdade formado por professores do próprio curso, eleitos entre seus pares, além de representante do corpo discente e dos diretores ou diretores adjuntos de Faculdade. Os diretores ou diretores adjuntos de Faculdades são as instâncias executivas de coordenação de ensino de cada curso.

Até 1998 a escolha para coordenador do curso era por eleição direta; a última foi em 1996. O corpo docente, discente e corpo técnico escolhiam e mandavam uma lista para a reitoria, que decidia. Em 1998 a mantenedora assumiu a direção da instituição e passou a indicar o reitor e as duas vice-reitorias, que escolhem os gestores das faculdades. As atribuições dos gestores são regimentais. Há um conselho de curso de cada faculdade com representação de professores, alunos e funcionários. O conselho é que define as diretrizes do curso, discute o projeto, contrata e demite docentes, gerencia conflitos. $O$ presidente do Conselho é o diretor da Faculdade. O conselho tem autonomia estabelecida em regimento, ele dá pareceres e é a instância de suporte à decisão.

O diretor de Faculdade tem diversas atribuições regimentais que envolvem questões como convocar e presidir o Conselho de Faculdade, coordenar a elaboração, a implantação, o desenvolvimento, a avaliação e o aperfeiçoamento do projeto pedagógico do curso, constituir comissões internas, planejar e apresentar à diretoria de Centro a proposta de infraestrutura necessária ao adequado funcionamento do curso, informar, aconselhar e orientar os alunos quanto ao funcionamento da universidade, processo de matrícula, regime escolar, currículos, estágios, iniciação científica, monitoria e outras informações relevantes, assessorar, supervisionar e orientar os professores sobre os procedimentos didático pedagógicos do curso, promovendo ou solicitando os necessários aperfeiçoamentos e correções, articular-se com órgãos da administração para fins de assistência vocacional, psicológica e social do aluno, bem como de preparação para sua inserção no mercado de trabalho até questões como acompanhar e orientar as relações interpessoais entre professores, funcionários e alunos, cooperar na divulgação, junto ao corpo docente, discente e técnico-administrativo do curso, das atividades de pesquisa e extensão e promover a articulação do curso com entidades científicas, tecnológicas e de ensino para intercâmbio, troca de experiências e inovações tecnológicas, dentre outras atribuições.

A segunda instituição é uma universidade pública estadual criada em 1976, a partir de institutos isolados de ensino superior que existiam em várias regiões do Estado de São Paulo. Tem 34 unidades em 24 cidades do estado de São Paulo. É uma das três universidades públicas de ensino gratuito e é mantida pelo Governo do Estado de São Paulo. A IES pesquisada possui 38.247 alunos em cursos de graduação e 14.431 alunos em cursos de pós-graduação. Oferece 183 opções de entrada na graduação e 149 na pós-graduação. A análise da gestão de curso de graduação terá como referência um dos diversos cursos oferecidos pela IES em uma unidade universitária que teve origem na Faculdade de Filosofia Ciências e Letras, criada pelo governo do Estado em 1958 e que compreende hoje duas unidades universitárias.

\begin{tabular}{|l|l|l|l|l|} 
Regae: Rev. Gest. Aval. Educ. & Santa Maria & v. 8 & n. 17 & Pub. contínua 2019 \\
\hline
\end{tabular} 
A sua estrutura é baseada em departamentos reunidos em Institutos ou Faculdades - unidades universitárias - integrados em campus. Cada unidade universitária possui uma Congregação, órgão deliberativo e normativo em matéria de ensino, pesquisa, extensão universitária e administração, com representação de toda a comunidade universitária.

A diretoria da Unidade Universitária é exercida pelo diretor, auxiliado pelo vicediretor. O Departamento é a unidade básica da estrutura universitária e integra, para efeito de organização didático-científica e administrativa disciplinas afins de um campo do conhecimento. A coordenação de curso de graduação nem a figura do coordenador de curso de graduação aparecem no estatuto e regimento da IES.

Existe uma resolução da Reitoria da IES que dispõe sobre a coordenação de cursos de graduação. Nesta resolução estabelece-se que a coordenação das atividades de cada curso de graduação será exercida, em cada unidade universitária, por um Conselho de Curso, presidido pelo coordenador de curso. Cada Conselho de Curso é composto por representantes docentes e discentes. O mandato dos membros do conselho é de dois anos para docentes e de um ano para representantes discentes, permitidas reconduções. O coordenador e vice-coordenador de curso são eleitos pelos membros do Conselho de Curso, dentre os representantes docentes titulares. A resolução que dispõe sobre a coordenação de cursos de graduação define competências e atribuições tanto para 0 Conselho de Curso de Graduação, quanto para o coordenador e vice-coordenador de curso de graduação.

Dentre as competências do coordenador de curso, destacamos: presidir o Conselho de Curso de Graduação, cumprir e zelar pelo cumprimento das deliberações do Conselho de Curso de Graduação e convocar, periodicamente, reuniões plenárias para discussão das atividades de rotina, bem como para avaliação anual das atividades do curso, e para a elaboração de propostas de alteração ou de reestruturação curricular. As competências do Conselho de Curso são mais amplas e numerosas, envolvendo definir, acompanhar e avaliar a proposta pedagógica do curso, coordenar as ações de ensino de graduação, propor normas para estágios curriculares, trabalhos de conclusão de curso, atividades complementares e atividades acadêmico, científicas e culturais, orientar alunos na matrícula, analisar e aprovar programas para alunos participarem de intercâmbio, coordenar e analisar o processo de avaliação do conteúdo ministrado e do desempenho didático dos decentes, avaliar anualmente o curso, manifestar-se nos processos de contratação docente para disciplinas do curso no que diz respeito à definição dos programas e provas, a composição de bancas examinadoras, ao perfil e preparo dos candidatos.

\section{Os modelos de gestão de cursos de graduação nas duas universidades}

Distintas organizações, distintos ambientes, distintas são as formas de dirigi-las na busca de seus objetivos. Os gestores dos cursos, diretor ou coordenador, em maior ou menor grau de intensidade ou atividades sob sua responsabilidade respondem a um objetivo final que é o mesmo, ou seja: fazer com que o ensino e a aprendizagem aconteçam conforme preconizados nos projetos pedagógicos dos cursos.

Entretanto as particularidades e características de cada uma das instituições irá tornar distinta a atuação do gestor. 
A primeira delas são as de restrições orçamentárias. Mesmo na instituição privada estudada que não tem como objetivo o lucro financeiro, sua restrição orçamentária está exatamente na potencialização de economia que gera para poder financiar o seu próprio desenvolvimento e atualizações dos seus cursos de graduação, nas suas atividades de extensão e de pesquisa. Embora a gestão do orçamento, neste caso, não caiba ao diretor do curso, muitas vezes impõe-se economias orçamentárias equivocadas uma vez que a decisão de investimento ou de qualquer despesa não rotineira tenha que passar sobre 0 crivo da administração superior da Universidade.

$\mathrm{Na}$ instituição pública, embora as restrições orçamentárias sejam uma realidade, a realização de um orçamento serve como base para o planejamento do ano seguinte. Sofre, é claro, com as dificuldades de repasses do governo, mas consegue decidir sobre o destino dos recursos e prioriza-los. Além disso, a aplicação do recurso deve ser realizada sob pena de que caso não o use, seja retirado no próximo exercício. Entretanto o que de fato decidirá o modelo de gestão do curso e a atuação do gestor é a forma de escolha para executar esta tarefa.

$\mathrm{Na}$ instituição privada, o processo de escolha do diretor de Faculdade acontece, geralmente, pela indicação superior que pode ou não ouvir ou consultar a comunidade acadêmica ou aos seus pares. Se de um lado esta conduta facilita a escolha de um gestor alinhado e identificado com a Administração Superior, algumas vezes competências e habilidades podem ser desconsideradas na escolha favorecendo, neste caso, as preferências pessoais dos principais gestores.

$\mathrm{Na}$ universidade em questão há a limitação de dois mandatos consecutivos de quatro anos cada um, para todos os seus gestores. De reitor aos diretores de faculdades os dois mandatos, pelo espírito do regimento quando criado, procurava evitar a perpetuação das pessoas nos cargos de gestão que antes de 1998 e eleições diretas, se julgava à época um inconveniente na renovação e alternativa na condução da universidade e seus cursos.

Na prática o que tem acontecido é que, no que diz respeito à condução dos cursos e os projetos pedagógicos, há uma tendência de centralização das decisões com pouca flexibilidade na elaboração dos mesmos. Todos os focos dos diretores estão no cumprimento de resoluções normativas e normas regulamentadas pela interpretação dada pela administração superior da instituição. A obediência aos requisitos do sistema acadêmico procura evitar qualquer decisão que não esteja prevista ou regulamentada. Isso traz uma padronização encaixotada na construção e formatação dos projetos pedagógicos dos cursos e impactam diretamente na gestão. O diretor, na maior parte do tempo, atende as demandas superiores sempre com prazos exíguos para o cumprimento e dando atenção a rotina interminável dos cursos para imputá-las no sistema de gestão acadêmico.

O que em princípio deveria ser um facilitador da gestão acaba tomando um tempo precioso para o desenvolvimento do curso e atuação junto aos alunos, corpo docente e a melhor compreensão do projeto pedagógico e na sua efetividade.

A esse respeito na instituição pública, em função da forma da escolha mais democrática, o coordenador deve possuir características mais mediadoras no processo de gestão. Mesmo eleito com o voto da maioria e sua gestão compartilhada com um Vice Coordenador e o Conselho, o coloca numa posição mais negociadora. Com decisões

\begin{tabular}{|l|l|l|l|l|l|} 
Regae: Rev. Gest. Aval. Educ. & Santa Maria & v. 8 & n. 17 & Pub. contínua 2019 & p. $1-16$ \\
\hline
\end{tabular} 
tomadas em colegiados e executadas a partir deste aval a tendência é de que pode haver um entendimento melhor por parte do corpo docente dos objetivos a serem alcançados as limitações de recursos e os caminhos a serem seguidos.

Entretanto, a mediação não é algo simples de ser conseguido e a habilidade do coordenador em relação às pessoas e sua capacidade criativa em indicar caminhos, encontrar atalhos, se relacionar em todos os níveis da instituição, sobretudo no apoio de seus pares consomem boa parte de seu tempo. Em áreas mais ideológicas tais como: das ciências sociais, as ciências humanas, a economia, o direito, um coordenador identificado com determinado pensamento sempre trará certa desconfiança sobre sua gestão e isso certamente fará com que boa parte de seu tempo seja dedicada a convencer as pessoas a compreenderem suas intenções.

Novamente se retoma a questão: qual o modelo de gestão adequado?

1) Quem assume a gestão precisa certamente conhecer, aplicar e entender as ferramentas de gestão adequadas para a instituição e os objetivos a serem alcançados.

2) Uma instituição de ensino não pode ser medida exclusivamente pelos seus resultados econômicos e financeiros.

3) Os resultados acadêmicos precisam ser ponderados considerando o potencial do seu alunado e a capacidade de transformação, competência e habilidade de seu corpo docente.

4) A estrutura organizacional deve estar aderente ao objetivo estratégico da instituição.

5) As estratégias de ensino podem ser mudadas entendendo que as condições ambientais se alteram e o caminho, em função disso, pode ser mudado.

6) Os objetivos da instituição precisam estar claros para o gestor e seu compromisso com os objetivos.

7) A administração superior precisa estar de mesma forma esclarecida quanto aos objetivos e se portar como a verdadeira patrocinadora da ação dos seus gestores.

Estabelecidos tais pontos é que se desenha o modelo que possa representar a complexidade da instituição ou curso administrado podendo escolher a partir da teoria geral da administração um modelo mais mecanicista ou orgânico de gestão de curso, no entendimento de Russo (2004) a administração é orientada pelo projeto políticopedagógico que se manifesta na prática por ações que possam "contribuir para que com os recursos existentes e disponíveis, se produza o máximo de educação possível, ou seja, que a escola atenda o maior número de alunos com a melhor qualidade" (p. 33).

\section{Considerações finais}

O trabalho se propôs a discutir o papel, o perfil e os desafios do coordenador de curso como gestor acadêmico, identificando modelos de gestão em uma universidade pública e em uma universidade privada. Evidencia-se a importância do coordenador de curso de graduação após as recentes políticas públicas para o ensino superior brasileiro, ocorridas desde meados da década de 1990. Não há bibliografia específica que aborde a complexidade do trabalho do coordenador, enquanto gestor educacional. A escassa produção acadêmica sobre esse assunto tem caráter prescritivo-normativo, dificultando uma discussão teórica que trate das especificidades da gestão educacional. 
Na maioria dos casos a gestão educacional se vale do paradigma da administração empresarial, tendo por pressuposto a ideia de que administrar uma escola é equivalente à administração de uma empresa qualquer. A partir de Russo (2004) e Goldbarg (1998) trazemos a especificidade da gestão educacional e a premência de se construir uma Teoria da Administração Escolar, alicerçada na educação como direito e na gestão democrática. Ao nos debruçarmos sobre os modelos de gestão de cursos em uma universidade pública e em uma universidade privada, a partir de pesquisa documental e observação participante, percebemos que 0 modelo de gestão tradicional ainda predomina, seja por questões de estratégia, estrutura organizacional, ambiente externo, objetivos e posicionamento.

\section{Referências}

ABREU, Bergamini de. Novas reflexões sobre a evolução da teoria administrativa: os quatro momentos cruciais no desenvolvimento da teoria organizacional. Revista de Administração Pública, Rio de Janeiro, v. 16, n. 4, 1982, p. 39-52.

AKTOUF, Omar. A administração entre a tradição e a renovação. São Paulo: Atlas, 1996.

ARAGÃO, José Euzébio de Oliveira Souza; FRANÇA, Carlos Marshal; ZUCCOLOTTO, Paulo Antonio da Graça Lima. Avaliação do ensino superior: os desafios para o Coordenador de Curso. In: ARAGÃO, José Euzébio de Oliveira Souza; ESCRIVÃO FILHO, Edmundo. Introdução à administração: desenvolvimento histórico, educação e perspectivas profissionais. São Paulo: Atlas, 2016, p. 145-160.

CATANI, Afrânio Mendes; OLIVEIRA, João Ferreira de. As políticas de diversificação e diferenciação da educação superior no Brasil: alterações no sistema e nas universidades públicas. In: SGUISSARDI, Valdemar (org.). Educação superior: velhos e novos desafios. São Paulo: Xamã, 2000, p. 63-81.

FERREIRA, Ademir Antônio; REIS, Ana Carla Fonseca; PEREIRA, Maria Isabel. Gestão empresarial: de Taylor aos nossos dias. São Paulo: Pioneira, 1997.

FRANCO, Édson Raymundo Pinheiro. Funções do coordenador de curso: como construir o coordenador ideal. Brasília: ANMS, 2002. Disponível em http://www.abmes.org.br /public/arquivos/publicacoes/ABMESCaderno8.pdf. Acesso em 17 ago. 2017.

GOLDBARG, Marco César. Educação e qualidade: repensando conceitos. Revista Brasileira de Estudos Pedagógicos, Brasília, v. 79, n. 193, 1998, p. 35-62.

JACOBUCCI, Daniela Franco Carvalho; JACOBUCCI, Giuliano Buzá. Correndo na esteira rolante: a experiência de coordenar um curso de graduação em uma instituição de ensino superior privada. Olhar do Professor, Ponta Grossa, v. 11, n. 1, 2008, p. 81-101. Disponível em http://www.uepg.br/olhar de professor. Acesso em 17 ago. 2017.

MAXIMIANO, Antonio César Amarú. Teoria geral da administração: da revolução urbana à revolução digital. São Paulo: Atlas, 2012.

MOTTA, Paulo Roberto. Gestão contemporânea: a ciência e a arte de ser dirigente. Rio de Janeiro: Record, 1999.

NOGUEZ, José Hiram S; TILLMANN, Alfredo Luiz da Costa; DUARTE, Glaucius Décio. Os saberes e práticas do coordenador de curso de graduação da Universidade Federal de Pelotas. REUNIÃO CIENTÍfICA REGIONAL DA ANPED, 11, 2016. Anais ... Curitiba: Anped, 2016. Disponível em http://www.anpedsul2016.ufpr.br/trabalhos-completos-eixo-8ensino-superior. Acesso em 17 ago. 2017. 
NUNES, Thalita Pimentel; LEÃO, Jacqueline Oliveira. O coordenador de curso de instituição de ensino superior privado como ferramenta de gestão estratégica universitária: um estudo de caso em uma instituição de Montes Claros/MG. Cadernos Zygmunt Bauman, v. 5, n. 9, 2015. $\quad$ Disponível em http://www.periodicoseletronicos.ufma.br/index.php/bauman/article/view/3813/1936. Acesso em 17 ago. 2017.

PEREIRA, Maria Isabel; SANTOS, Silvio Aparecido dos. Modelo de gestão: uma análise conceitual. São Paulo: Pioneira Thomson Learning, 2001

ROBBINS, Stephen P. O processo administrativo: integrando teoria e prática. São Paulo: Atlas. 1978.

RUSSO, Miguel Henrique. Escola e paradigmas de gestão. EccoS - Revista Científica, São Paulo, Uninove, v. 6, n. 1, 2004, p. 25-42.

SILVA, Reinaldo O. Teorias da administração. São Paulo: Thomson Pioneira, 2001.

José Euzébio de Oliveira Souza Aragão é professor no Departamento de Educação e no Programa de Pós-Graduação em Educação do Instituto de Biociências da Universidade Estadual Paulista Júlio de Mesquita Filho, campus de Rio Claro.

Orcid: https://orcid.org/0000-0003-3284-0189.

Endereço: Avenida Paulo de Arruda Corrêa da Silva, 303 - 13575-842 - São Carlos SP - Brasil.

E-mail: aragao@rc.unesp.br.

Paulo Antonio Da Graça Lima Zuccolotto é professor assistente na Pontifícia Universidade Católica de Campinas e diretor da Faculdade de Administração.

Endereço: Avenida Contábile Romano, 3058 - 14096-275 - Ribeirão Preto - SP Brasil.

Orcid: http://orcid.org/0000-0003-3992-5222.

E-mail: pzuccolotto@terra.com.br.

Maria Aparecida Bovério é professora titular da Faculdade de Tecnologia, campus de Sertãozinho.

Orcid: http://orcid.org/0000-0003-0259-4909.

Enderço: Alameda João Hernandes, 41 - 15-900-000 - Monte Alto - SP - Brasil.

E-mail: mariaboverio@hotmail.com.

Vanessa Terra Pereira é bacharel em Biblioteconomia pela Universidade Estadual de São Paulo, campus de Marília.

Endereço: Rua São Benedito, 625/21 - 15910-000 - Monte Alto - SP - Brasil.

Orcid: https://orcid.org/0000-0002-3543-4533

E-mail: vantpereira@gmail.com.

Recebido em 22 de agosto de 2018.

Aceito em 9 de novembro de 2018. 